This item was submitted to Loughborough's Research Repository by the author.

Items in Figshare are protected by copyright, with all rights reserved, unless otherwise indicated.

\title{
Mathematics coursework as facilitator of formative assessment, student- centred activity and understanding
}

PLEASE CITE THE PUBLISHED VERSION

http://dx.doi.org/10.1080/14794802.2011.585830

\section{PUBLISHER}

Taylor \& Francis (Routledge) @ 2011 British Society for Research into Learning Mathematics

\section{VERSION}

AM (Accepted Manuscript)

\section{LICENCE}

CC BY-NC-ND 4.0

\section{REPOSITORY RECORD}

Hernandez-Martinez, Paul, Julian Williams, Laura Black, Pauline Davis, Maria Pampaka, and Geoff Wake. 2019. "Mathematics Coursework as Facilitator of Formative Assessment, Student-centred Activity and Understanding". figshare. https://hdl.handle.net/2134/8819. 
This item was submitted to Loughborough's Institutional Repository (https://dspace.lboro.ac.uk/) by the author and is made available under the following Creative Commons Licence conditions.

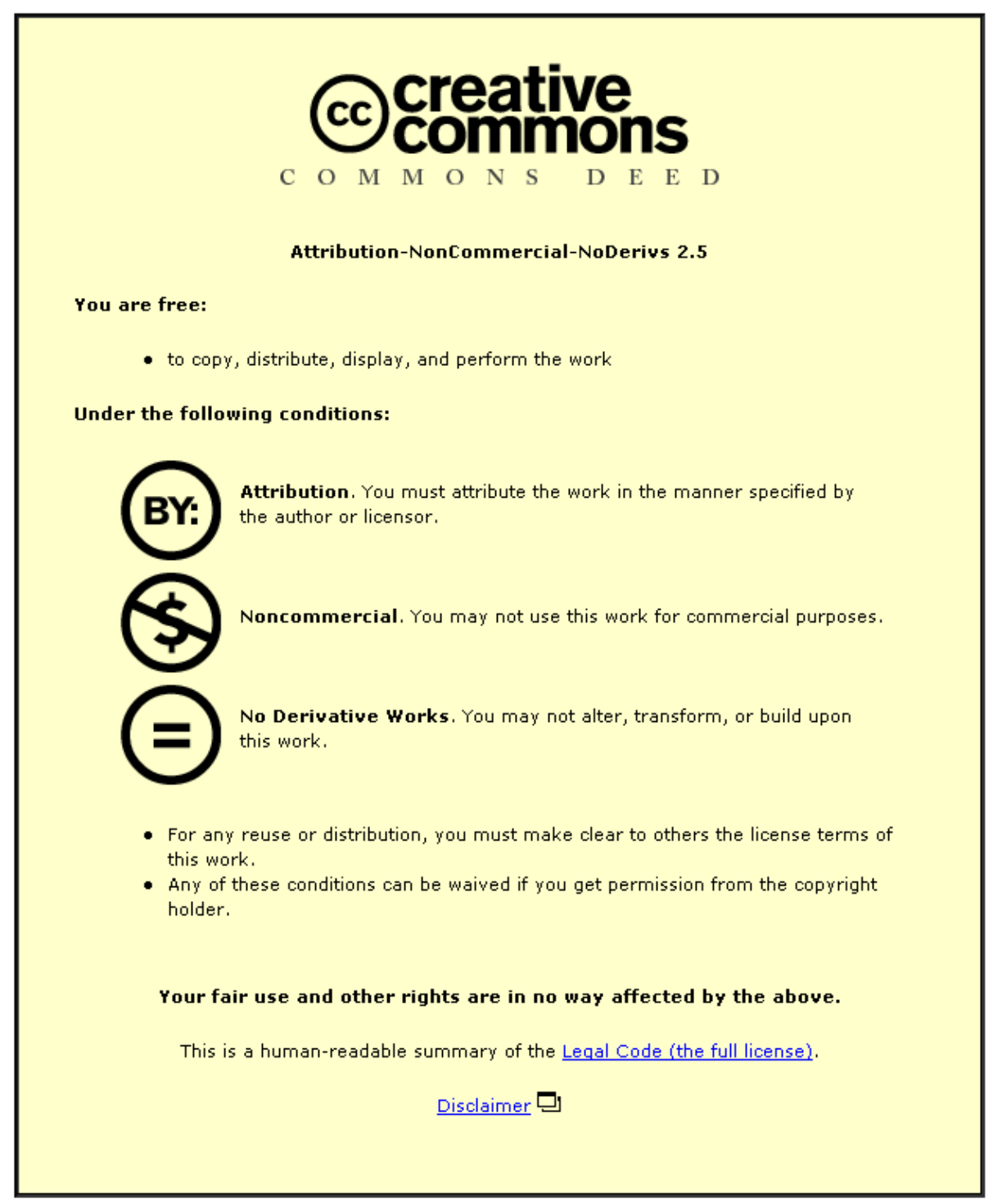

For the full text of this licence, please go to: http://creativecommons.org/licenses/by-nc-nd/2.5/ 


\title{
Mathematics coursework as facilitator of formative assessment, student-centred activity and understanding
}

\author{
Paul Hernandez-Martinez ${ }^{\mathrm{a}}$, Julian Williams ${ }^{\mathrm{b}}$, Laura Black $^{\mathrm{b}}$, Pauline Davis ${ }^{\mathrm{b}}$, \\ Maria Pampaka ${ }^{\mathrm{b}}$ and Geoff Wake \\ ${ }^{a}$ Loughborough University, UK; ${ }^{b}$ University of Manchester, UK; ${ }^{c}$ University of Nottingham, UK
}

\begin{abstract}
We seek to illuminate reasons why undertaking mathematics coursework assessment as part of an alternative post-compulsory, pre-university scheme led to higher rates of retention and completion than the traditional route. We focus on the students' experience of mathematical activity during coursework tasks, which we observed to be qualitatively different to most of the other learning activities observed in lessons. Our analysis of interviews found that these activities offered: (i) a perceived greater depth of understanding; (ii) motivation and learning through modelling and use of technology; (iii) changes in pedagogies and learning activities that supported student-centred learning; and (iv) assessment that better suited some students. Teachers' interviews reinforced these categories and highlighted some motivational aspects of learning that activity during coursework tasks appears to provide. Thus, we suggest that this experience offered some students different learning opportunities, and that this is a plausible factor in the relative success of these students.
\end{abstract}

Keywords: mathematics coursework; student-centred activity; understanding

\section{Introduction and background}

Participation in mathematics at post-compulsory, pre-university level (i.e. A-level ${ }^{1}$ ) in the UK has been of major concern in recent years. Since the publication of the Roberts' Report (2002), that highlighted the shortage of students going into careers demanding high levels of mathematics, and the Smith Inquiry report (2004), about the teaching and learning of mathematics post-14, the government has sought to identify ways in which to increase the take-up and retention of students taking mathematics in post-compulsory education (QCA 2006a). Our project Keeping Open the Door to Mathematically-Demanding Further and Higher Education Programmes sought to better understand how to extend and improve the learning of mathematics, particularly by those 'on the edge' of participation in the post-compulsory, preuniversity sector. We surveyed students by large-scale questionnaire and interviewed a cohort of them on different occasions as they progressed through their first year of post-compulsory education (preceding the 'Advanced Supplementary', or AS level, examination). In addition, we developed case studies in five colleges ${ }^{2}$ across the UK where we observed two different and distinctive mathematics programmes and a diversity of pedagogies. Some of our conclusions are presented elsewhere in this Special Issue, and other outputs and further information can be found at the project's website ${ }^{3}$. 
Our perspective on teaching and learning is informed by activity theory, in the tradition of Vygotsky, Luria, Leont'ev, and their followers (Roth and Lee 2007). Thus, classroom teaching-and-learning is understood as a joint, collective 'activity' shaped by its motive of 'school learning' and its intended 'outcomes' of mathematics knowledge and test results. It is, further, crucially mediated by tools (the syllabus/ assessment, technologies, etc), the classroom division of labour and associated relationships, so norms of communication (between learners themselves, but also with teachers and significant others), and so on. The whole 'activity system' of social relationships must be thought of as a dynamic, living, organic social whole: its dynamic is explained historically by the internal contradictions between its elements, and between the system itself and others with which it interacts.

With respect to academic learning in particular, Vygotsky's position is quite specific (Vygotsky 1986): the personal, private 'intramental' mathematics learning of the students is a function of the internalisation of the mathematics that is first manifested socially and publically, intermentally, in joint activity and discourse, e.g. with other learners and the teacher in the classroom (or elsewhere where study takes place).

This paper in particular looks at classroom activity and discourse and learners and teachers reflections on this to illuminate the reasons why a significant number of our students following an alternative curriculum performed better than their peers (with similar prior attainment) on the traditional course. We draw on our own observations, but also on a systematic data analysis of students' and their teachers' own explanations. This alternative qualification, Use of Mathematics, was mostly designed on the principles of 'mathematical modelling' and is assessed through coursework (33\%) and timed-written examination $(67 \%)$, with two of three constituent modules being assessed through these elements in equal weight, and the final module being entirely assessed by timed-written examination. The 'traditional' course, followed by the vast majority of the age cohort, involves no coursework, or a very small amount that relates to collecting and analysing data in statistics, and it is assessed mainly by timed written examinations, contrasting starkly with the Use of Mathematics course.

Data from our project published elsewhere (Pampaka et al. 2011) reveal that some students (particularly those with lower prior grades) undertaking the course leading to Use of Mathematics were more likely to complete their AS course in the expected first year of study than the matching students on the traditional course (i.e. students with similar prior attainment in mathematics $\mathrm{GCSE}^{4}$; see Table 1).

Now, in looking at the different learning outcomes from two different programmes, the activity theory perspective tells us that we must look to the 'social whole' of the activity constituted in the two courses. But the essential distinctive, defining difference between the two courses is actually in the assessment scheme. We, therefore, look to this scheme, but with the perspective that the difference between the schemes is only of relevance to the extent that it mediates and shapes the whole activity, that is the learning and teaching activity, its norms of communication, the tools used, etc.

A plausible explanation might be that the teachers' pedagogy in the two courses was different: this was explored in Pampaka et al. (2011) where it is reported that 


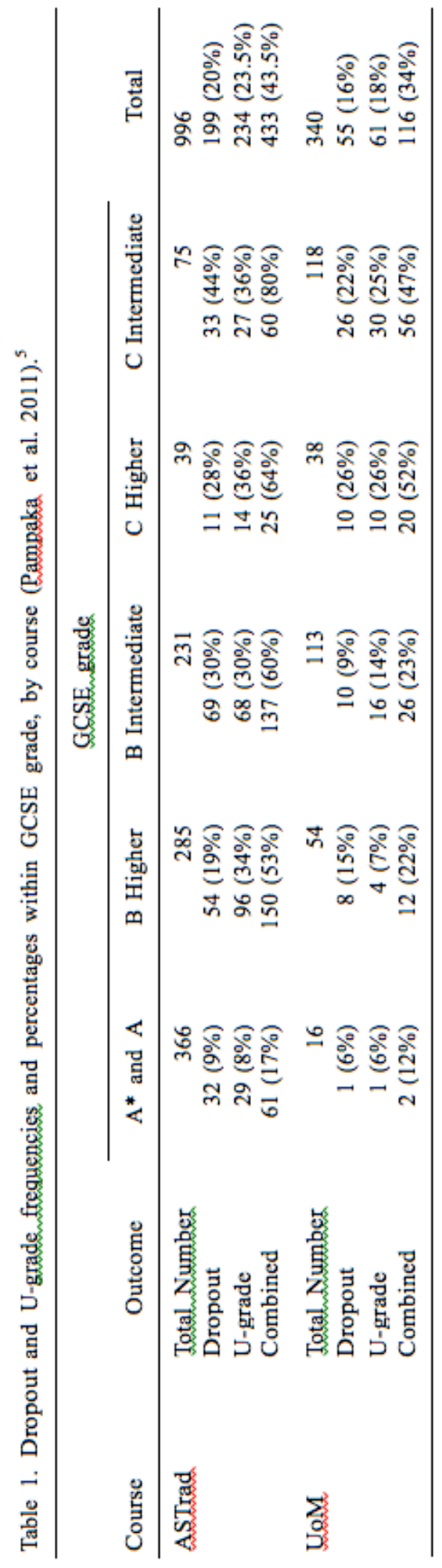


teachers' perception of their classroom practice (whether student-centred or teachercentred) was not significantly different between the two courses, nor was it measurably significant on examination outcomes. Yet, we insist that the teachinglearning activity must have been different. In this paper, then, we turn towards the learning experience of the students, and consider how coursework assessment tasks might provide distinct learning opportunities. We ask: do the assessment practices afforded by the Use of Mathematics programme support different students' opportunities to learn, and hence offer progress with mathematics, and if so what are they and how do they help?

There could be a number of reasons for the enhanced progress we have found, as the two groups are different in a number of ways, including: Use of Mathematics students are generally weaker in prior attainment, and they tend to include more students whose aspirations to study more mathematics are lower than those following the traditional mathematics course. Such lower aspirations would seem likely, given that at the time of study the Use of Mathematics course terminated at AS level, which does not normally provide for progression to mathematical courses in Higher Education (An A2 Use of Mathematics was being piloted, and if successful, would make this qualification available also at A-level, thus allowing for progression). Also, colleges might have lower aspirations for these students due to the fact that Use of Mathematics is a less high-stakes course, and therefore colleges are likely not to encourage students with low grades, or who are performing poorly, to drop out.

In this paper, we hypothesise that one key factor in the success of the alternative Use of Mathematics award in retaining students for longer may have been the different experience of learning mathematics afforded by the required 'coursework assessment tasks'. These, more or less, oblige teaching-learning interactions that focus on students' mathematics, their understanding, their ability for problem solving and their communication of mathematics. Thus, each student's understanding of mathematics tends to come to the fore in coursework tasks in ways that seem rare in traditional classroom pedagogic interactions, where the focus on the students' own mathematics tends to be procedural rather than conceptual (Hiebert 1986). Here, we argue that this might be the key to explaining the differences in student performance on the two courses.

Although this argument is one that is consistent with previous literature and our own observations, here we derive some support for this view from the analysis of students' and their teachers' accounts/explanations, given to us in interview data. Following a brief overview of the Use of Mathematics qualification and a vignette of the type of classroom activity that we observed in coursework lessons, we identify four main themes that we determine as having impact on student learning and attitudes that emerge from our analysis of students' interviews. We find that teachers' perceptions of the value of coursework tasks in their teaching support these emergent themes, as they are perceived to support a formative assessment agenda that shifts the focus from teaching to learning.

\section{The Use of Mathematics qualification and coursework}

Use of Mathematics aims to promote: the application of mathematical principles, the development of skills that support communication, use and interpretation of 
mathematics, the solution of substantial and realistic problems, the ability to solve open-ended problems, the development of mathematical modelling and reasoning skills, the appropriate use of technology (e.g. graphic calculators, spreadsheets), and the enjoyment of mathematics (AQA 2008). Most of these aims are manifestly and explicitly supported by the materials on the internet (www.fsmq.org developed and maintained by the Nuffield Foundation) and a series of textbooks (Haighton, Haworth and Wake 2003a, 2003b, 2004). Teachers can either develop coursework tasks that relate directly to their students' studies, work or interests or access a bank of coursework projects from which to choose, and which they can modify according to their needs.

For instance, in the core module 'Working with algebraic and graphical techniques', students are expected to learn how to use a graphic calculator or graph plotting software in order to fit different functions to data, interpret models and know how to use different algebraic techniques. These skills must be evidenced in each student's coursework, with their developing portfolio being assessed under each of three themes: structuring and presenting work, using appropriate mathematics and working accurately, and interpreting mathematics.

\section{Literature on coursework}

The use of coursework in England was introduced some years ago, with the intention of assessing 'particular skills and topics that are, by their nature, unsuitable for assessment within a timed examination but are, nonetheless, important aspects of the specification' (Porkess 2006, 5). Emphasising the positive learning aims of coursework, Pirie $(1988,7)$ states that the introduction of investigational work in school mathematics and of assessment by coursework had, as one of its aims, to encourage students 'to create their own mathematics: actively taking part in mathematical thinking rather than passively receiving mathematical thought'. However, Morgan (2006, 230) points to the different discourses and values surrounding the use of coursework in mathematics at school, and the tensions that exist among them:

The discourse surrounding the notion of 'investigation' in school mathematics in England introduces values related to, among others, exploration, creativity, originality and the nature of mathematical activity that are at times in tension with the values of the dominant assessment discourse, including reliability and comparability.

More recently, it seems that this latter discourse has permeated mathematics curricula at all levels, in great part facilitated by the practical problems encountered by teachers when implementing and assessing coursework. In its consultation with teachers about the use of coursework at GCSE, the Qualifications and Curriculum Authority (QCA 2006b, 2) found that:

The evidence relating to mathematics GCSE coursework was striking. In contrast with all other subjects a substantial majority of mathematics teachers $(66 \%)$ disagreed with the proposition that coursework was valid and reliable. In addition, the mathematics teachers showed the highest levels of concern about different aspects of coursework, such as authenticating candidates' work. There was particular criticism by teachers of the data-handling aspect of mathematics coursework; this was felt to be too open-ended and to rely too much on students' literacy. 
From the 2007 examination onwards, coursework has been discontinued from GCSE mathematics and almost all A-level mathematics specifications do not currently contain coursework.

However, Little (2007) reported on a survey of students' opinion (n 228) about coursework at A-level that most considered coursework positively; few considered it unfair; and girls seemed to be more favourably disposed than boys (this could be potentially important if we are interested in increasing female participation in a traditionally male-oriented subject like mathematics).

These conflicting views suggest that it is necessary to consider and investigate the benefits that the particular activities facilitated by coursework can bring in terms of the learning opportunities and the engagement of students; as opposed to the practical problems for teachers and examiners that assessing coursework pose. For example, Hunt $(2005,13)$ comments:

It is not coursework that is the problem, but the teachers of mathematics who have been unable/unwilling to integrate coursework into the mathematics curriculum. Integration of coursework into the curriculum would not only negate the argument that coursework is too time-consuming and is of limited educational value, but would develop in students the ability to use and apply their mathematics. This would greatly improve the students' understanding, but would also allow the gifted students the tools they need for further study within the subject.

To illustrate exactly what might be meant by these 'benefits', we present a vignette of a coursework lesson that we observed in one of our case studies; this type of lesson was observed in the three of our five case study colleges that offered the Use of Mathematics qualification. In each of these, we observed several lessons given by at least two different teachers. Here, this vignette highlights features that we found to be generally distinct in the coursework lessons that we observed, and that we believe might make a difference for some learners.

\section{Vignette of a coursework lesson}

The lesson started with the teacher, Jeremy ${ }^{6}$, asking students to sit in pairs in front of a computer. He took the first $5-10$ minutes of the lesson to address the students and explain the purpose of the coursework: students were asked to plot three points (each student had their own data) using Autograph, a dynamic graph-plotting software package for teaching and learning mathematics. They were expected to use this to find a quadratic graph fitting the three points. In other words, they had to explore, using the computer, and find values for the parameters $\mathrm{a}, \mathrm{b}$ and $\mathrm{c}$ for a quadratic function expressed in the general form $y=x^{2}+\mathrm{b} x+\mathrm{c}$ that provided a good fit to the data. Finally, using the properties of their graph, they had to express their quadratic function in the 'completed square' form [i.e. $y=\mathrm{r}(x-\mathrm{h})^{2}+\mathrm{k}$, where the vertex of the parabola is in $(\mathrm{h}, \mathrm{k})]$.

Once explanation of the task was over, the students got on with their work, but instead of this being silent, individual work, students discussed their work between themselves, with the teacher and with other groups sometimes with groups that were on opposite sides of the classroom. Jeremy only approached a group if they asked him to do so. 
A pair of students asked about the form of the quadratic equation. Jeremy explained: "This is the form you had [i.e. the general form] and this [i.e. the completed square form] is a different form. OK? Which we're going to use to shift things about a bit (i.e. transform one into the other). OK? Alright? See if you can do that." Another pair asked for feedback on their model. Jeremy asked:

Is that your best attempt? It's pretty good. Make a note of it. But of course, it's not perfect, is it? You've lowered that (pointing to the value of a), you could probably lower the others. So you've managed to delineate those lines. The model that exists for this part only exists up to that point.

Jeremy then commented on a neighbouring group's work:

That looks pretty good to me. You found the vertex. It's a bit too far to the left. The computer's great for that ... it lets you move the graph around, left to right, up and down in a predictable way. The other form, which is easier, if you start changing these round (the values of the parameters), you can't predict exactly what it's going to do but that's the advantage. Can you sort of zoom out and show me? I know why, do you know why?

A pair of students, struggling to understand why their model did not go exactly through one of their points (even when they zoomed in), asked Jeremy for help. However, another pair at the other side of the classroom (and obviously struggling with the same problem) shouted an answer across the room ('the model will never be exact').

This vignette highlights a different type of mathematical activity in coursework lessons, compared to what we observed in most non-coursework lessons. In the vast majority of (non-coursework) lessons, we observed the teacher beginning by demonstrating how to solve a problem (usually one that related directly to one on a test paper to come) with some variants, and then asking students to solve similar problems (each taking between one and ten minutes) that gradually increase in difficulty, while the teacher monitors progress. In coursework tasks, students have a relatively open problem with defined objectives, and they begin to explore different solutions, perhaps with the help of tools such as a computer, over an extended period of time. There is usually active engagement with students in discussion with their peers and the teacher, and most importantly, there is constant feedback on each learner's own mathematics from different sources (teacher, computer, peers). The initiative for this feedback often comes, when there is a perceived need, from the student, not the teacher. The students are, to a certain extent, free to decide how to solve the problem. This cycle of interaction and feedback can go on for days (the tasks normally take two weeks to be completed and handed in to the teacher). This can allow time sometimes needed for ideas and concepts to become clear. It is worth mentioning that this kind of activity satisfies Sadler's (1989) conditions for effective feedback, that is, the development of ways and means for reducing the discrepancy between the actual level or quality of a student's work and the standard or goal.

We see this as a relatively student-centred and more dialogical activity, where more effective formative feedback can occur. Swan (2006) argues that a studentcentred approach to learning can prove more effective in developing students' understanding of, and attitudes towards, mathematics. Black and Wiliam (1998) also 
argue that practices of formative assessment produce significant, and often substantial, learning gains. In this article, we will claim that the particular mathematical activity in coursework i.e. students being responsible for, and taking control of, their learning, by exploring different solutions, comparing different approaches, making and justifying decisions and discussing their ideas with the teacher and classmates and asking for help when needed, all of which can promote deeper learning and understanding (Askew et al. 1997) was reflected in the discourses of teachers and learners about coursework in our interviews. We propose that it is precisely this experience that can help students persist and succeed with mathematics.

\section{Method/ology}

The wider project adopted a mixed method design, including ethnographic observations, case study work and a large sample survey from which the data in Table 1 is taken (involving a number of measures of student outcomes; for example, see Pampaka et al. 2011). However, in addressing our question here, we draw on data from documents and observations in the field as above, and teachers' and students' interviews that focused on their perceptions of their mathematics learning experiences (Pampaka, Kleanthous and Hutcheson this issue).

In our case studies, the Use of Mathematics qualification was offered as either an alternative to the traditional mathematics A-level or alongside the $\mathrm{BTEC}^{7}$ qualification in engineering. In the cases explored here, we interviewed three teachers about their practices, usually immediately after observing, and relating to, a particular lesson. We asked them about what they thought they did during that lesson (we observed them in both coursework and non-coursework lessons). We also interviewed 45 students across both AS mathematics courses: 22 students following a traditional AS mathematics course and 23 following an AS Use of Mathematics course (10 of these within a BTEC course). Table 2 shows a classification of these students by award studied and gender. Most of these students were selected for interview because they were considered to be at risk of dropping out of their respective mathematics courses.

Students were interviewed on at least three different occasions: at the beginning of the year, at the end of the AS year and early in the following year, when most of them had completed their university entrance application UCAS $^{8}$ form, although six of them had dropped out, or were repeating a year and so had not yet applied to university). The majority of interviews were biographical in nature, and were conducted in an open way to explore with students their past and present experiences and future intentions with regard to mathematics. In mid year we also made a 'pedagogical' interview with some of the students (31 in total, 17 from the traditional course, 10 from the Use of Mathematics-BTEC course and four from the Use of

Table 2. Student interviewees classification by award studied and gender.

\begin{tabular}{ccccc}
\hline & Traditional AS Mathematics & & \multicolumn{2}{c}{ AS Use of Mathematics } \\
\cline { 1 - 2 } \cline { 4 - 5 } Males & Females & & Males & Females \\
\hline 14 & 8 & 15 & 8 \\
\hline
\end{tabular}


Mathematics course), in which we focused specifically on the 'pedagogy' of a recent lesson and the students' perception of this. Thus, in the majority of cases, if 'coursework' was raised as an issue by the interviewer or the student, this would be because it was thought relevant in this context: these interviews were not 'about coursework' per se, but about what was thought relevant to their learning, past and future (we thought that this design would help ensure that beliefs or perceptions about coursework were heartfelt, and not artificial constructions of the interview method).

Student interviews were transcribed and systematically coded using the software Atlas.ti (http://www.atlasti.com) and, for this analysis, all utterances that explicitly or implicitly referred to 'coursework' or 'projects' were selected for thematic analysis. Teacher interviews were transcribed, and in a similar way to the students' interviews, all quotes referring to 'coursework' were selected and analysed.

\section{Results/Analysis}

Students' perceptions of coursework

Use of Mathematics students

An Atlas.ti query of these students' interviews produced 97 selections/quotes drawn from 21 students (10 BTEC and 11 non-BTEC) from the colleges where Use of Mathematics was taught. The themes arising from these students' quotes were: (i) understanding mathematics; (ii) modelling and technology; (iii) pedagogy/learning; and (iv) assessment and performance.

Understanding mathematics. Students talked about understanding, connecting, meaning-making and explaining mathematics through coursework. Coursework is understood by these students as offering opportunities to develop their understanding, through being required to explain or discuss mathematics, to make connections within mathematics and to connect mathematics to other areas. Most of these students spoke of this positively. For example, Frank, a BTEC student, talked about coursework as being different from his other lessons and as a way to understand, to 'grasp' mathematical knowledge by having to do the work himself:

Int: So you're saying when you had the lessons, you sometimes didn't understand everything but now you're doing the coursework, somehow you've got to...

F: Grasp of it.

Int: Yeah. Why's that, do you think? Is that difficult to...

F: Because of doing the work myself.

Marc talked about how, in coursework, he has to 'research', make judgements and apply concepts previously learned, which in turn makes it 'hard' (although this doesn't mean he has a negative attitude towards coursework). Mitch also finds coursework hard, but he also recognises that what makes it hard (researching, connecting, and explaining the maths) allows him to gain a far greater conceptual understanding than any he could have obtained in the traditional course, where 'they just go through piles of questions'.

Modelling and technology. Students talked positively about how their coursework was applied to other subjects. In particular, the vocational engineering (BTEC) students saw coursework as an opportunity to apply mathematics to projects in 
engineering and technology. Modelling was often described as a process of fitting models (usually functions via their graphs) to data representing some real situation, much as in the lesson vignette we presented above.

For example, Ernest (BTEC student) talked about how enjoyable coursework was where he had to fit a model by adjusting certain parameters:

Int: So in general how did you find the coursework?

E: It wasn't so difficult. I enjoyed doing it.

Int: You enjoyed it.

E: Yeah. I learned a lot because of it.

Int: Could you tell me which parts of this assignment did you enjoy more?

E: Fitting the model. It's good when the model is perfect, or almost perfect. To see that your parameters are very good so... yeah.

Peter also talked about how he used the computer in his coursework, and how he was able to understand an equation and how, as its values changed, its graph 'curved'. The use of technology for coursework is referred to by some of these students in a positive way, as in the case of Jamie, who thought that the computer helped him in checking mistakes and visualising a graph.

Pedagogy/learning. For these students, coursework related to various learning experiences that were different from those in their 'normal lessons', offering a different way to learn. Coursework for them involved research, working on their own, but also discussing with other students and even getting help from teachers in a 'different' context. All this was generally seen as positive. For example, for Hector (BTEC student), coursework involved him in research and working things out, which is something 'quite good', and from which he has 'learned a lot'.

Edward (also BTEC student), said that talking to his teacher about his coursework allowed him to monitor his own progress and ask questions, and to discuss his 'theories' with his 'mates', which allowed him to see if he was going in the right direction, to compare and see "if you are not doing something right".

In a similar way, Alan thinks of coursework as a way to get feedback on his work, so that the teacher can tell him "this is what you need to improve", and he "can go away and improve it", which for him is a "lot better way of teaching". And Adam, who "didn't do too well" in finance-related coursework (he got a C), realised that he needed to ask the teacher because "in a normal lesson, if you don't ask for help, you won't get it". For some students, coursework not only provided an opportunity to get help from the teacher, but also to learn with others, to have a social support group. Finally, coursework was seen by some as writing an essay, which is a positive experience, especially for students like Alan who are 'a klutz with exams' and find coursework 'more supportive'.

Assessment and performance. Many of these students talked about coursework being easier than exams, saying it offered them a chance to improve their grades or ameliorate their poor exam performance. For example, Paul (BTEC student) said his coursework would boost his grades, even though he did not finish it all, and Jared talked about this in a very positive way:

Int: So how do you think it will go at the end?

J: $\quad$ I think I'll be fine this year, I do understand it and it's not that I have a big head or anything but I think I can get an A or B... because it's $50 \%$ coursework as well... 
(...)

Int: Do you enjoy it?

J: Yes because that's when you know that you can get a good grade ... 'cos last year when I did pure and statistics [the traditional course] there was no coursework and I just hated that but this year it's $50 \%$.

Like Jared, Alan also talked about enjoying coursework, or feeling more comfortable with it than with other types of assessment, because "you do it in your own time" without the pressure of having to finish an exam in time and get all answers right.

However, some BTEC students refer to coursework in relation to the stress of having to work to a deadline and the overload of work when deadlines for other subjects' coursework come all at once. But, in general, many talked about how coursework is less stressful than exams, and so coursework is sometimes said to be 'easier' than exams, giving them more confidence. Like Alan, John also talked about coursework as a relief from the stress of exams, "the pressure of sitting for an hour in an exam", and how he feels more confident about his coursework.

\section{Traditional AS Mathematics students}

A query of these students' interviews produced 19 selections/quotes which were mainly about coursework in other subjects or mathematics at GCSE, but many of these comments support those of the Use of Mathematics students above. For example, Ambar talked about her coursework in applied sciences, where it counts as half the grade, and she is doing well on it. She would have liked to have had coursework in her mathematics course to 'balance' a likely bad performance in the exam, where there is a time pressure. However, even though coursework had features that she likes, she also mentioned the overload of work with other subjects, and thinks that not having coursework in mathematics is a 'relief'.

Susan talked about her mathematics coursework at school, where she enjoyed it 'because it was more interesting than just working out of a book kind of thing'. Fabio, for example, talked about the fact that coursework at GCSE was easier than exams, and how coursework provided him with the opportunity to work collaboratively. As before with the Use of Mathematics students, those who considered themselves 'good at writing' found coursework easy, and a way to enhance their marks. For example, Will, who is thinking of taking a mathematics degree at university, talked about how he finds it easy to 'write stuff down', as he obtained high grades in English GCSE.

However, there were a few students who reported that they did not like coursework, for example Jason, who said he was 'too lazy to do coursework', and Simon, who considered that 'writing is not proper maths'. As a consequence of this dislike, in Simon's GCSE course he did not consider coursework important enough to do it properly, which in turn compromised his good marks in the examination, reducing his overall grade. However, some successful mathematics students told us that they preferred examinations to coursework, mainly because they said that they have always been successful in them. These student views suggest that, particularly for those who would find the traditional approach difficult or unsupportive, coursework might provide an opportunity to progress where they might otherwise 
fail. Indeed, we might speculate that one way of encouraging students who have dropped out of mathematics to re-engage would be to promote coursework as a means of affording learning opportunities that would help. Our data suggest coursework can provide for activity in which mathematics understanding may arise in different ways, sometimes by engaging in a practical problem, by the use of technology, and by student-centred activity that allows exploration and creativity.

\section{Teachers' perceptions of coursework}

The teacher interviews revealed that teachers' attitudes to coursework reflected the same themes that we identified through our analysis of student interviews. This is, perhaps, not surprising, as the practices that are central to the mathematical experiences of the Use of Mathematics students are ultimately controlled by their teachers. However, the requirement that the students produce coursework provides the catalyst that ensures that these practices are developed within the mathematics programme. In general, however, teachers' views in relation to coursework might be characterised as being focused on formative assessment practices (assessment for learning) (Black and Wiliam 1998). In practice, teachers perceive the use of technology in this regard as essential. Ruth, who teaches the programme in the same college as our vignette lesson, explained how use of the computer and graphic calculator forces students to show their mathematical work, how 'they arrived at a particular situation', and even provided them with a tool to 'check that their algebra is true'. Thus, feedback to students comes immediately and directly from their own work with the technology, in addition to anything they get from their teacher.

Our vignette teacher, Jeremy, also emphasised how coursework allows students to work on one substantial task over a substantial period of time (different from an 'exercise'), and how students are motivated and 'really want to succeed' as they work to the solution:

I think coursework is good because it focuses them on a substantial task you know ... it's not as if they are doing an exercise because the teacher asked them to do and they can probably get away with copying somebody else's work or you know even a good student might just do it in a mechanical way whereas they really want to succeed in the coursework and you get those sorts of situations such as we had time for yesterday because if you say three weeks for this one topic you know...

This teacher also perceives that coursework tasks help him 'map' where students are, and feels this is important for effective feedback to "bridge the gap between what learners know and what they need to know before they can successfully learn from the task at hand" (Kyriacou 1997, 24).

Another (the third) teacher, Sandra, said that coursework, as a structured piece of work, should encourage independent learning and thinking. She said:

It's a structured piece of work. I mean, it does help, I suppose, that they've done the skills in it and it should, theoretically, if they've had, it's sort of forcing them to think more about things. It should help the coursework because it's all about showing evidence of independent research and thinking so it should ... that should theoretically have a knock on effect, shouldn't it? 
All these teachers' views are consistent with the proposition that the mathematical activity facilitated by coursework can provide a different experience of mathematics to that considered normal or typical in non-coursework lessons, suggesting that it may be valuable for all students, but especially for those who are likely to have trouble with the regular non-coursework activity. They all argue that the mathematical learning activity that is made possible through coursework allows for relatively student-centred learning activity, which, from these teachers' point of view, motivates students' interest in understanding, and communicating or explaining their solution to a problem. It also provides what Sadler (1989) calls 'formative feedback'.

\section{Conclusion}

Most of the Use of Mathematics student sample would, by virtue of their prior grades, normally be considered 'at risk', or mathematically 'weak' for postcompulsory mathematics courses (at Advanced level), and from the data presented in Table 1 it would be reasonable to suppose that they might not have completed a traditional AS in mathematics, had they started that route. However, it seems plausible that activity during coursework lessons offered these students possibilities to experience understanding and connection-making within mathematics and between mathematics and other subjects, and that this experience might have contributed to the confidence shown by such students in persisting with mathematics. The teachers support the use of coursework for assessment because of the potential the activity offers in supporting opportunities for investigation and discussion, time for reflection, and a way to find misconceptions, which in turn allows for more effective feedback. Teachers appreciate the formative role that coursework activity affords, and students and teachers also articulated the advantages that the use of the computer in coursework tasks can bring, as a way to model real situations and check students' work, helping them to monitor their own progress, and providing another source of feedback.

Some students refer to coursework as providing a less stressful means of assessing their mathematical knowledge than timed examinations, and this may also enhance student confidence and encourage them to persist. Many students believed that coursework assessment helped them achieve better grades. In contrast, it is worth noticing that some other students, who do well in exams, do not like coursework; nevertheless the so called 'high attainers', for whom written examinations do not present so much difficulty, might also benefit from the advantages that we have described here. In our 'Transmaths' projects', we found that many students with high mathematics grades have only a procedural understanding of mathematical concepts, and find their conceptual understanding fragile when they become involved in advanced studies at university. In our view, the importance of the mathematical activity that is facilitated by coursework to students' perception of their own 'understanding' is the key to confidence: weaker students who disengage from mathematics often say they do so because they 'did not understand'. The stronger students may say they don't understand, but this worries them less as long as they perform the procedures successfully. Thus, we suggest that the discourse of understanding is particularly crucial for students that the system struggles to keep engaged. But, we also have some grounds to argue that the 'understanding' teachers 
and students speak of is 'practical' as well as discursive: references to the need to communicate and explain mathematics implies a degree of conceptual depth, as do references to 'investigation', 'research' and independent thinking and motivation, in completing substantial tasks which we observed in actual practice.

It is very important to note that we are not suggesting that it is coursework per se that enhances mathematical engagement, but rather that it is the mathematical activities afforded by coursework tasks. We found that the activities observed during these coursework assessment lessons and tasks included practices that students said helped their understanding and confidence, and afforded them different, general- ly social, ways to learn that included dialogue and feedback. Mathematics can be taught in similar ways without coursework, and we have indeed exceptionally seen some such teaching in 'traditional' mathematics courses: conversely, coursework does not necessarily lead to rich mathematical activity; in other contexts we imagine that coursework could be ineffective. However, we think that the coursework in Use of Mathematics has been shown to encourage activity that promotes mathematical engagement, and we would also signal some other beneficial effects on student outcomes; for instance, another analysis found significant differences in what the different groups of students said about the 'uses' of mathematics (Davis 2009).

The fact of the relative success in Use of Mathematics for lower-attaining (prior grade $\mathrm{B} / \mathrm{C}$ ) students has to be explainable, and the discourse of students and teachers in relation to the type of mathematical activity that goes on during coursework tasks is a plausible explanation for this, in the light of previous literature on studentcentred activity, formative assessment and understanding in mathematics. To this we add a caveat: the term 'understanding' in the students' and teachers' interviews is always open to question and multiple interpretation. Sometimes students may say they 'get it' when they feel they can correctly follow a procedure: thus 'understanding' what is going on can be conflated with procedural rather than conceptual grasp (Hiebert 1986). Yet the communication between students and between student and teacher, and the requirement of coursework to give explanations, does lean in the direction of enhanced conceptual understanding.

Thus, with all these caveats, we argue that coursework encouraged a different kind of mathematical activity than the one typical in non-coursework tasks and lessons, and was plausibly part of the explanation why the Use of Mathematics course achieved relatively successful participation results. The implications for policy and practice, then, are to weigh this effect in the balance, e.g. against the reluctance of teachers to engage with coursework assessment at this level, which of course involves factors including professional development that are beyond the scope of this paper.

In summary, we found that coursework was seen by our teachers and students as allowing activity that could be described as student-centred, in the sense that students take more control of their own learning by exploring a problem for themselves (here the graphic calculator and the computer can be crucial tools). This includes discussing ideas with classmates and their teacher, but the learner taking decisions and justifying them, while the teacher's role could be more to facilitate. This student-centredness is arguably essential for the development of learners' understanding, confidence and motivation (Swan 2006). It also allows for formative assessment, through feedback that can help to bridge the gap between what learners 
know and what they need to know before they can successfully learn from the task at hand' (Kyriacou 1997, 24).

We believe that the benefits that the type of activities observed in coursework lessons and tasks can bring to the teaching and learning of mathematics, especially to those 'hard' to reach, should influence policy, despite the practical problems that teachers have reported, and which led coursework to be discontinued as a way to assess mathematics GCSE and A-level.

\section{Acknowledgements}

This research has been funded by the ESRC-TLRP ${ }^{10}$ under the project Keeping Open the Door to Mathematically-Demanding Further and Higher Education Programmes (RES-139-25-0241) and by the ESRC under the project Mathematics Learning, Identity and Educational Practice: the Transition into Post-compulsory Education (RES-000-22-2890). We would like to acknowledge their continued support.

\section{Notes}

1. A-level stands for 'Advanced level' which is a post-compulsory education qualification (normally taken at the age of 18) and the most frequent route into Higher Education. A-levels can be chosen from various academic and applied subjects (normally 3 or 4 depending on interests and future plans). It normally takes two years full-time to complete an A-level, and each one is made up of AS (Advanced Subsidiary first year) and A2 (second year), each of which counts 50 percent of the overall A-level grade.

2. A Sixth Form College (or just college) is an educational institution in the UK where students typically study for advanced school qualifications at post-compulsory/preuniversity level, such as A-levels or other vocational qualifications.

3. www.education.manchester.ac.uk/research/centres/lta/LTAResearch/transmaths/tlrp/

4. GCSE is the General Certificate of Secondary Education, and is the academic qualification awarded at the end of compulsory schooling in specified subjects, including mathematics and English.

5. At the time of the study there were three Mathematics GCSE tiers: Foundation, Intermediate and Higher. It was possible to attain a grade $A^{*} D$ by sitting Higher tier examination papers, a grade B E by sitting Intermediate tier papers and a grade D G by sitting Foundation tier papers. However, since 2006 there are only two mathematics GCSE tiers: Foundation, where is possible to attain C G grades, and Higher, where is possible to attain $A^{*} \mathrm{D}$ grades. Each paper examines material at the level appropriate to these grades, and the content includes topics in number and algebra, geometry, measures and statistics and probability.

6. All names (teachers and students) in this paper are pseudonyms.

7. BTEC stands for Business and Technical Education Council, and refers to the body that awards these vocational qualifications in different subjects.

8. UCAS, the Universities and Colleges Admissions Service, is the central organisation through which applications are processed for entry into Higher Education in the UK.

9. For more information see the 'Transmaths' project website: www.education.manchester. ac.uk/research/centres/lta/LTAResearch/transmaths/

10. The Educational and Social Economic Research Council (ESRC) is the UK's social research council that funds academic research in the social sciences, including Education. The ESRC, using university sponsorship, fund the Teaching and Learning Research Programme (TLRP) to conduct educational research in teaching and learning for over ten years in multiple phases, including one on Widening Participation in Higher Education in 2005-08. See www.tlrp.org 


\section{References}

AQA 2008. Free-standing mathematics qualifications - Advanced level 2010. Manchester: Assessment and Qualifications Alliance.

Askew, M., M. Brown, V. Rhodes, D. Wiliam, and D. Johnson. 1997. Effective teachers of numeracy. London: King's College.

Black, P., and D. Wiliam. 1998. Assessment and classroom learning. Assessment in Education 5, no. 1: 7-73.

Davis, P. 2009. Participating differently in mathematics: The role of an exchange/use value dialectic. Paper presented at the 2009 AERA Conference, San Diego, California. http:// www.aera.net.

Haighton, J., A. Haworth, and G.D. Wake, eds. 2003a. AS: Use of maths. Algebra \& graphs. Cheltenham: Nelson Thornes.

Haighton, J., A. Haworth, and G.D. Wake, eds. 2003b. AS: Use of maths. Statistics. Cheltenham: Nelson Thornes.

Haighton, J., A. Haworth and G.D. Wake, eds. 2004. AS: Use of Maths. Calculus. Cheltenham: Nelson Thornes.

Hiebert, J. 1986. Conceptual and procedural knowledge: The case of mathematics. Hillsdale, NJ: Erlbaum.

Hunt, D. 2005. In praise of GCSE coursework in mathematics. Mathematics in Schools 34, no. 5: $12-23$.

Kyriacou, C. 1997. Effective teaching in schools: Theory and practice. Cheltenham: Nelson Thornes.

Little, C. 2007. A coursework task in A-level mathematics a survey of student opinion. Proceedings of the British Society for Research into Learning Mathematics 27, no. 3: 78- 83. Morgan, C. 2006. What does social semiotics have to offer to mathematics education research? Educational Studies in Mathematics 61: 219-245.

Pampaka, M., I. Kleanthous, G. Hutcheson, and G. Wake. 2011. Measuring mathematics selfefficacy as a learning outcome. Research in Mathematics Education 13, no. 2: 169-190.

Pampaka, M., J. Williams, G. Hutcheson, G. Wake, L. Black, P. Davis, and P. HernandezMartinez. 2011. The association between mathematics pedagogy and learners' dispositions for university study. British Educational Research Journal. First published online on 15 April 2011 (iFirst).

Pirie, S. 1988. GCSE coursework: Mathematics. London: Macmillan.

Porkess, R. 2006. Coursework in mathematics: A discussion paper. MEI. http://www.ima.org. uk/Education/courseworkmei.pdf.

QCA. 2006a. Evaluation of participation in A-level mathematics (interim report Autumn 2005). Coventry: Qualifications and Curriculum Agency.

QCA. 2006a. 2006b. GCSE mathematics coursework consultation summary. Coventry: Qualifications and Curriculum Agency.

Roberts, G. 2002. SET for success: The supply of people with science, technology, engineering and mathematics skills. The report of Sir Gareth Roberts' review. London: HM Treasury.

Roth, W.-M., and Y.-J. Lee. 2007. "Vygotsky's neglected legacy": Cultural historical activity theory. Review of Educational Research 77, no. 2: 186- 232.

Sadler, D.R. 1989. Formative assessment and the design of instructional systems. Instructional Science 18: 145-165.

Smith, A. 2004. Making mathematics count: The report of Professor Adrian Smith's inquiry into post-14 mathematics education. London: The Stationery Office.

Swan, M. 2006. Learning GCSE mathematics through discussion: What are the effects on students? Journal of Further and Higher Education 30, no. 3: 229-241.

Vygotsky, L.S. 1986. Thought and language. Cambridge, MA: MIT Press. 